\title{
Nanomedicine: towards development of patient-friendly drug-delivery systems for oncological applications
}

REVIEW

This article was published in the following Dove Press journal:

International Journal of Nanomedicine

22 February 2012

Number of times this article has been viewed

\section{Ramya Ranganathan ${ }^{1, *}$ \\ Shruthilaya Madanmohan I,* \\ Akila Kesavan' \\ Ganga Baskar' \\ Yoganathan Ramia \\ Krishnamoorthy ${ }^{2}$ \\ Roy Santosham ${ }^{3}$ \\ D Ponraju ${ }^{4}$ \\ Suresh Kumar Rayala ${ }^{2}$ \\ Ganesh Venkatraman' \\ 'Department of Human Genetics, Sri Ramachandra University, Porur, ${ }^{2}$ Department of Biotechnology, Indian Institute of Technology, Madras, ${ }^{3}$ Department of Radiology and Imaging Sciences, Sri Ramachandra University, Porur, Chennai, ${ }^{4}$ Safety Engineering Division, Nuclear and Engineering Safety Group, Indira Gandhi Center for Atomic Research, Kalpakkam, India \\ *Authors contributed equally to this work}

Correspondence: Ganesh Venkatraman Department of Human Genetics, Sri Ramachandra University, Porur, Chennai 600116, India

Tel +9l 4424765512 ext 237

Fax +9l 4424767008

Email gvenkat16@gmail.com

Suresh Kumar Rayala Department of Biotechnology, Indian Institute of Technology, Madras, Chennai, 600036, India

$\mathrm{Tel}+9 \mid 4422576137$

Fax +9I 4422574102

Email rayala@iitm.ac.in

\begin{abstract}
The focus on nanotechnology in cancer treatment and diagnosis has intensified due to the serious side effects caused by anticancer agents as a result of their cytotoxic actions on normal cells. This nonspecific action of chemotherapy has awakened a need for formulations capable of definitive targeting with enhanced tumor-killing. Nanooncology, the application of nanobiotechnology to the management of cancer, is currently the most important area of nanomedicine. Currently several nanomaterial-based drug-delivery systems are in vogue and several others are in various stages of development. Tumor-targeted drug-delivery systems are envisioned as magic bullets for cancer therapy and several groups are working globally for development of robust systems.
\end{abstract}

Keywords: patient-friendly, drug-delivery systems, cancer, nanomedicine

\section{Introduction}

Nanotechnology is the latest hype of modern technology and has applications in several human disease-related problems. Nanotechnology refers to the understanding and control of matter at dimensions between approximately 1 and 100 nanometers, where unique phenomena enable novel applications. Dimensions between approximately 1 and 100 nanometers are known as the nanoscale. Unusual physical, chemical, and biological properties can emerge in materials at this scale and these properties may differ in important ways from the properties of bulk materials and single atoms or molecules. Nanotechnology has been applied in varied fields like electronics, energy, space, medicine, food, and chemical sensors and in molecular manufacturing. Nanomedicine is a branch that focuses on application of nanotechnology in faster diagnosis, enhanced therapeutics, improved imaging, and prevention of various clinical conditions. In particular, it is used in drug delivery, diagnosis, imaging, and therapy. There are several nanomaterial-based agents under various stages of development with applications in medicine and some are in clinical use. With the changes in disease incidence, mortality, and treatment response for chronic ailments like cancer, neurodegenerative disorders, or metabolic syndrome, there is a need for development of newer technologies for early and rapid diagnosis and new safe drugs for treatment. Nanotechnology-based agents have given many promising leads in such areas. Among many areas, cancer nanotechnology or nanooncology has been a notable area of interest for several groups. Currently there are several nanomaterial-based agents for cancer therapy in the clinics and several others in varying stages of development. This review will discuss the diverse applications of nanotechnology, particularly in the field of cancer therapy. 


\section{Nanotechnology in medicine}

A nanoparticle (NP) is defined as the smallest unit $\left(10^{-9}\right.$ meters) that can still behave as a whole entity in terms of properties and transport. NPs are particulate dispersions or solid particles ranging from 10 to $100 \mathrm{~nm}$ in size (in one dimension) and are being developed to: improve drug bioavailability, abrogate treatment-induced drug resistance, and reduce nonspecific toxicity in the field of medicine. Several recent studies have shown that nanomaterials are able to cross biological membranes and access cells, tissues, and organs that larger-sized particles normally cannot. Based on the chemical nature of the preparations, there are diverse types of nanoparticles that have been synthesized and evaluated. Nanomaterial-based agents used for drug delivery include carbon NPs, dendrimers, ceramic NPs, chitosan NPs, liposomes, low-density lipoproteins, nanoemulsions, and nanospheres, etc. ${ }^{1}$ In all these types, drugs can be absorbed onto the surface, entrapped inside, or dissolved within the matrix of the NPs.

Recent advances in medicine and health care have greatly improved the life span of humans. This increase in life span also comes with an increased risk for several types of cancer, as cancer is considered as a disease of old age. It is also true that, during aging, individuals present with several comorbidities along with their diagnosis of cancer. Hence there is an increasing need to develop new agents for therapy of cancers that is effective and addresses such associated risks. Currently, chemotherapy using cytotoxic agents is the main stay for treatment of several malignancies. ${ }^{1}$ Besides, cytotoxic chemotherapy, antihormone therapy, moleculartargeted therapies are also practiced, either single agent or in combination with conventional therapies. But several issues including costs and nontarget toxicity limit such combination treatments. Hence, there is a need to develop novel agents for treatment of cancers, which are less toxic, affordable, and provide better quality of life.

\section{Limitations of current cancer treatment modalities}

Currently available chemotherapy agents are time-tested, and confer good disease-free survival for a limited period of time. Nevertheless, nontarget tissue toxicity and drug resistance curtails the utility of these agents. Thus there is scope to develop newer agents or site-specific delivery systems to transfer these chemotherapeutic agents, which can annul the important obstacles of toxicity and drug resistance.

\section{Nanoparticles as delivery vehicles}

Nanoparticle-based drug-delivery systems have made a remarkable difference in site-specific release of chemotherapeutic agents, owing to their physical and chemical characteristics and biological attributes. Research in this exciting area has been happening for more than two decades, but only in the last decade were several of these formulations released in the market and are now routinely used in clinics. This type of research is very promising and the conglomeration of expertise from a multidisciplinary team of polymer chemists, cancer biologists, and pharmacologists has seen several innovative agents become available.

\section{Contributions from basic cancer biology for drug delivery}

Research in the field of molecular oncology, which deals with basic disease mechanisms, has shown six important characteristics of tumor cells, referred as the "hallmarks of cancer". ${ }^{2}$ Sustained angiogenesis is one characteristic, which indicates that tumors develop their own blood supply from the existing host vessels for nourishment. Several studies on tumor vasculature have shown them to possess structural anomalies that impede drug delivery. The tumor vasculature is known to possess poor architecture with an abnormal basement membrane and fissures between the endothelial cells due to an absent pericyte lining. This state of leaky vasculature accompanied by a poor lymphatic drainage system causes a differential interstitial pressure at the center of tumors than at the periphery. Due to this pressure difference, molecules ranging from approximately $10 \mathrm{~nm}$ to $100 \mathrm{~nm}$, preferentially accumulate in the tumors and are retained longer, unlike the uncoated drugs, which are of much smaller size and cleared by the kidneys. ${ }^{3}$ This phenomenon is called the enhanced permeability and retention effect (EPR). A schematic representation of leaky vasculature and EPR is shown in Figure 1. Studies have shown that the retention time of drugs packed in NPs is ten times higher than that of unpacked drugs, which eventually return to the vascular system. ${ }^{4}$ Hence, this EPR effect attributed to the leaky vasculature is considered as a boon for drug-delivery systems within the nanosize range. A schematic representation for passive targeting of NPs owing to EPR effect in tumors is shown in Figure 2.

\section{Examples of nanomaterials used for drug delivery}

There is considerable flexibility in the choice of raw materials and the methods of synthesis which can be adopted to fabricate nanoscale drug-delivery systems based 


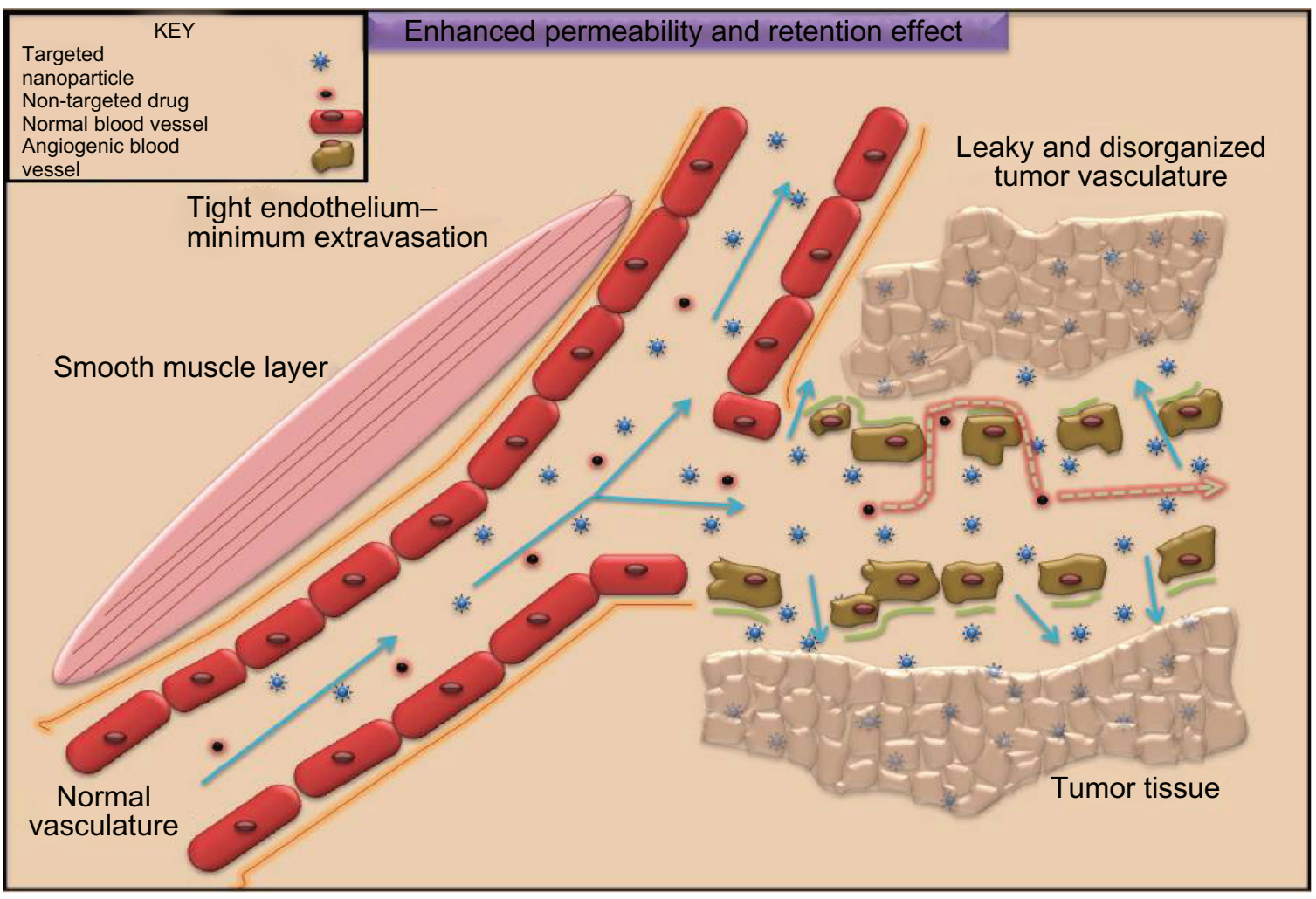

Figure I The enhanced permeability and retention effect operating in tumor milieu permitting accumulation of nanometer-sized particles in cancer cells. Blood vessels in tumor tissue have defective architecture with gaps as large as 200-1000 nm allowing nanoparticles to extravasate and accumulate inside the tumor tissue. The retention time of drugs packed in nanoparticles is ten times higher than that of unpacked drugs, which eventually return to the vascular system. This phenomenon of permeability of molecules due to their size is a boon to cancer therapy and is known as the enhanced permeability and retention effect.

on their application. In this review we shall discuss different kinds of nanomaterial-based drug-delivery systems, with a focus on their components, applications, advantages, and limitations of the preparations.

\section{Liposomes}

Liposomes are self-assembled phospholipid membranes with an inner core where drugs can be entrapped. Liposomes are relatively stable, biodegradable, and do not elicit any immune response. They are efficient vehicles for targeted delivery of hydrophobic drugs. Liposomes are vesicular formulations of lipid bilayers prepared synthetically. The water-soluble drugs are present in aqueous compartments while lipid-soluble drugs and amphiphilic drugs insert themselves in the phospholipid bilayer. Liposomes have been in vogue for varied applications such as DNA delivery in gene therapy and genetic engineering, drug delivery in nutrition and dietary supplements, or cosmetics. Liposomes may be synthesized in various sizes and shapes, however, nanoscale liposomes called nanosomes are of specific interest in targeting cancer. Such nanosomes are several nanometers in size and most commonly contain anticancer $\operatorname{drug}(\mathrm{s}){ }^{5,6}$ Since nanosomes are soluble in aqueous solvents (like blood), they can carry hydrophilic as well as hydrophobic molecules, thus allowing administration of anticancer drugs that showed poor efficacy due to their limited solubility. A nanosome is essentially a vesicular lipid bilayer with the polar heads facing the solvent and the tail regions facing each other. The anticancer drug, if hydrophobic, can thus be contained in the tail region, and if hydrophilic, solubilized in the liposomal core. Surface modification of liposomes using polyethylene glycol (PEG), confers the liposomes stealth property, from being destroyed by the reticuloendothelial system. PEGylated (STEALTH) liposomal doxorubicin (Doxil ${ }^{\circledR}$, Caelyx; Schering-Plough Pharmaceuticals, Kenilworth, NJ) was the first liposomal anticancer drug for the treatment of ovarian cancers to be approved by the US Food and Drug Administration. Several lipid-based formulations like liposomes have been synthesized and characterized. We will review significant types for their novelty in composition, synthesis, size, shape, and applications. Newer generations of liposomes containing two anticancer agents within a single liposome are under development. 


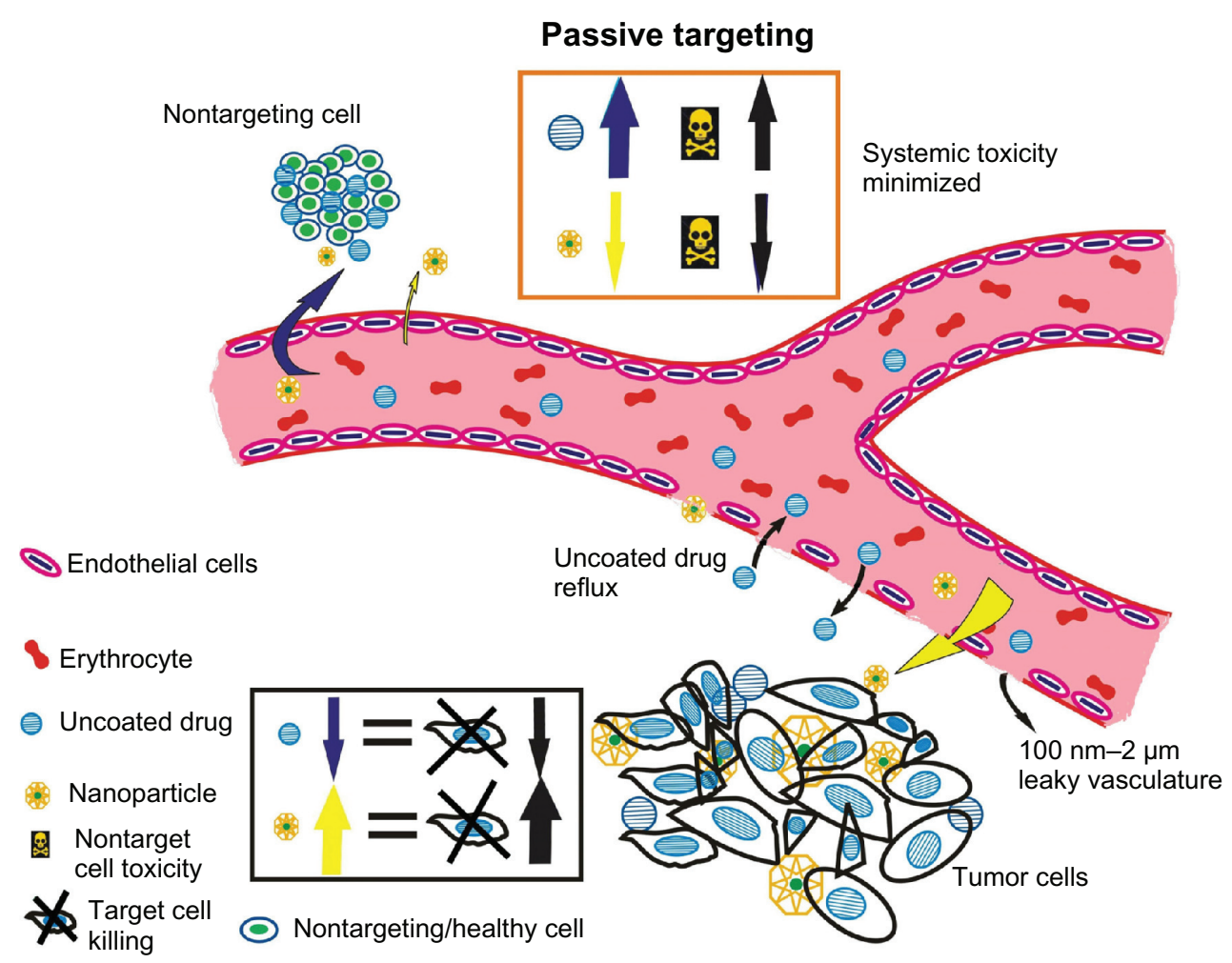

Figure 2 Passive targeting of nanoparticles to tumor cells according to tumor vasculature and size characteristics. Passive targeting of nanoparticles: nanoparticles (in yellow) concentrate to tumor sites taking advantage of leaky vasculature and diminished lymphatics. Tumor angiogenesis is torturous and aberrant with gap sizes of $100 \mathrm{~nm}-2 \mu \mathrm{m}$. Nanocarriers because of their small size can thus accumulate in tumor interstitium minimizing systemic toxicity and enhancing tumor cell killing. Free or uncoated anticancer drugs (blue) lack this advantage accounting for serious side effects due to extravasation to healthy cells and reflux at target sites. Yellow arrows indicate the extravasation of nanocarriers to the tumor site (indicated with thickened arrows, in addition, to represent higher biodistribution). Blue arrows indicate the extravasation of the uncoated drug to the nontargeting site rendering systemic toxicity, which is further thickened to symbolize higher concentration of the uncoated drug.

Lipid-based nanocapsules provide a novel approach for encapsulation of poorly soluble drugs like cisplatin or paclitaxel. Burger and colleagues developed a novel method for the efficient encapsulation of cisplatin in a lipid formulation based on repeated freezing and thawing of a concentrated solution of cisplatin in the presence of negatively charged phospholipids, namely dioleoyl-phosphatidylserine and dioleoylphosphatidylcholine. ${ }^{7}$ This method generated nanocapsules, composed of small aggregates of cisplatin covered by a single lipid bilayer. These lipid preparations showed an exceptional drug-to-lipid ratio and when tested on ovarian cancer cells, showed 1000-fold higher cytotoxicity when compared to free drug. Though cisplatin is the drug of choice for treatment of ovarian neoplasms in particular, its utility is limited in the clinical scenario because of its dose-limiting toxicity and acquired resistance. Hence it is imperative to develop delivery vehicles that can circumvent these issues. Several groups have attempted lipid-based nanoformulations for cisplatin delivery, but their application is limited due to cisplatin's poor water and lipid solubility. This study by Burger et al is unique because it had addressed these issues with a basic freeze-thaw method for a nanoformulation, using simple phospholipids. ${ }^{7}$
Several research groups have used numerous combinations of lipids to generate liposomes with ideal qualities. In one such attempt, researchers fabricated carboxylated hyperbranched polymeric liposomes that act on a $\mathrm{pH}-$ dependent stimulus. ${ }^{8}$ Hyperbranched 3-methyl-glutarylated poly(glycidol) (HPG) polymers have been constructed with varying degrees of polymerization and a co-pH-sensitive stimulus that showed enhanced uptake of the NP due to the presence of fusogenic active membranes. Such liposomes were built on the idea that the presence of fusogenic membrane active proteins conjugated on polymers would be stable prior to lipid membrane fusion but will relieve its contents when brought in contact with endosomal or lysosomal compartments within the cytosol. HPG polymers are similar to PEG chains except that such polymers bear carboxyl side groups and are complexly convoluted to give a three-dimensional (3D) spherical appearance rather than being linear. This 3D structure brings about steric hindrance that is required during membrane fusion. Many of these polymers are surfaceconjugated with viral fusogenic peptides that add to their endocytic uptake by the target cell. This novel approach acts as a potent substitute to poly(ethylene glycol) that provides a 
3D arrangement to liposomes which emphasizes cell membrane adhesion. Addition of fusogenic peptides like viral proteins further encourages effective target cell membrane fusion and eventually ensures endocytosis by target cells. Figure 3 depicts the performance and selective advantages of a stealth NP under in vivo systems.

Torchilin et al have reported enhanced efficacy of a tumorspecific monoclonal antibody possessing nucleosome-restricted specificity and conjugated to PEGylated-doxorubicin-loaded liposomes. ${ }^{9}$ The actively targeted liposome bears monoclonal antinuclear autoantibodies $2 \mathrm{C} 5$ that mediate cytotoxicity via antibody-dependent cell cytotoxicity (ADCC) and bind to tumor-specific surface-bound intact nucleosomes, stemmed from neighboring apoptotic tumor cells. A novelty in these targeted liposomes, is that the tumor-recognizing antibody, 2C5, is derived with PEG and then was inserted to the liposomal corona. Modification of the liposomes using this method yielded a stoichiometry of approximately 70 antibody molecules on the liposome surface, conferring a strong antigen-antibody interaction, favoring the delivery of the therapeutic load in to the tumor cells. Nanosized liposomes have also been enriched to approach issues like multidrug resistance commonly observed in administration of free drugs. This occurs due to action of adenosine triphosphate (ATP)-efflux pumps activated via P-glycoproteins. A finding has reported successful curtailment of cellular resistance and effective cell death by constructing a cationic liposome incorporated with doxorubicin and small-interfering RNA (siRNA) targeted to MRP1 and BCL2 mRNA. In this study a multifunctional cationic liposome has been fabricated which contains doxorubicin and siRNA to the multidrug resistance protein MRP1 and the antiapoptotic protein BCL2. Though the study had novelty in the synthesis of a system incorporating a therapeutic load and siRNA, had cell biology and in vitro studies, it did not show any data to substantiate the performance in vivo. Active targeting via novel stealth liposomes surface conjugated with fibronectin mimetics to specifically target tumor endothelial cells overexpressed with integrin alpha(5) beta(1) family has also been attempted. ${ }^{10}$ Nanosomes have also been diversified for diagnosis and imaging apart from tumor therapy. A recent study has reported the development of paramagnetic and fluorescent liposomes actively targeted to tumor angiogenesis by conjugating integrin alpha(5) beta(1) inhibitors. ${ }^{11}$

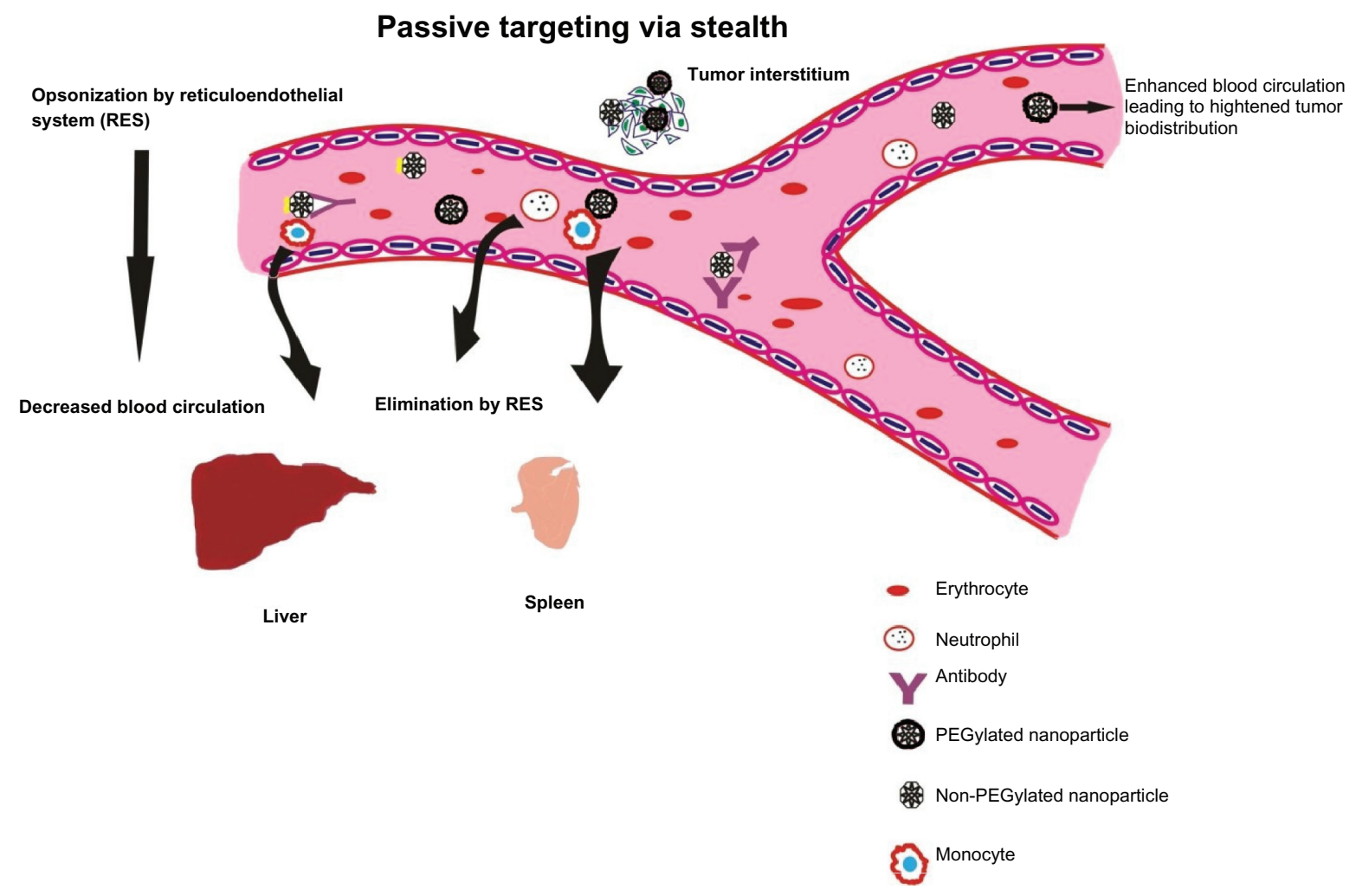

Figure 3 Passive targeting of nanoparticles to tumor cells with stealth characteristics to evade rapid destruction by reticuloendothelial system and excretion. Passive targeting of PEGylated nanoparticles. Nanoparticles surface coated with poly(ethylene glycol) (PEG) are capable of evading reticuloendothelial system (RES), thus delaying elimination to liver and spleen. Nanoparticles uncoated with PEG are easily recognized by the immune cells (phagocytes and monocytes) resulting in earlier elimination to liver and spleen. This results in decreased blood circulation and enhanced tumor localization of the anticancer nanovector. 
There are several dietary chemopreventive agents with potent bioactivity. Among such agents turmeric (Curcuma longa) is a crystalline compound commonly used in cuisine and for medicinal purposes in India. Curcumin (diferulomethane), a yellow pigment substance, is the active component of turmeric. Curcumin's efficacy as a chemotherapeutic agent against several cancers of the stomach, prostate, breast, and lung has been documented. ${ }^{12-14}$ The limitation in the clinical application of this agent is its poor bioavailability and hydrophobicity. Few research groups have started to fabricate nanomaterial-based delivery systems to circumvent such limitations. A recent study has reported the development of liposomal curcumin encompassing the anticancer curcumin within liposomal formulations. ${ }^{15}$ The efficacy of liposomal curcumin was examined on prostate cancer cell lines, $\mathrm{LNCaP}$ and $\mathrm{C} 42 \mathrm{~B}$, in vitro. Treatment of cells with liposomal curcumin for a period of $24-48$ hours resulted in suppression in cell proliferation to $70 \%-80 \%$ at a concentration of 5-10 $\mu \mathrm{M}$ on comparison of free or uncoated curcumin resulting in equal suppression at a concentration higher than $50 \mu \mathrm{M}$. In another study, liposome preparations of curcumin exhibited superior antiproliferative and apoptotic effects on six pancreatic cancer cells and also inhibited pancreatic tumor growth in mouse models. ${ }^{16}$ The in vivo studies also showed that liposomal curcumin preparations had better tumor inhibition capacity, and antiangiogenic effects compared with control vehicles, but this study did not include a group of animals treated with unpacked curcumin. The above-mentioned studies on curcumin indicate that nanomaterial preparations like liposomes are very useful in delivering such dietary compounds with poor solubility and hydrophobicity effectively to tumors.

While liposomes are associated with highlighted advantages over free drugs, they do exhibit serious toxicity like keratopathy, mucositis, and myelosuppression not seen on administration of free anticancer drugs. ${ }^{17}$ Even though many liposomal formulations are clinically available, many of these preparations have problems with circulation time and have been shown to evoke immune responses. Han and colleagues suggested incorporating a comb-like polymer comprised of poly(methyl methacrylate) side chain to further improve circulation time. ${ }^{18}$ Previous studies have also reported that the immune response is provoked due to polymers grafted on liposomal membrane and lipid dose. ${ }^{19,20}$ PEGylated liposomes elicit an anti-PEG IgM response in $\mathrm{T}$ cell-independent fashion while $\mathrm{B}$ cells may play a vital role in evoking immune response against empty PEGylated liposomes. ${ }^{21}$ This in vitro lymphocyte proliferation study published by Ishida showed that
PEGylated liposomes elicited a $\mathrm{T}$ cell-independent manner. The ELISA-based assay performed on blood of nude mice pretreated with the PEGylated liposomes showed a strong anti-immunoglobulin $\mathrm{M}$ (anti-IgM) response after 5 days and a weak IgG response. Though the description of liposomes as phospholipid bilayers with drug loads according to the biological resemblance seemed innocuous during the development, their performance on in vivo models have shown their limitations, which couldn't have been envisaged otherwise.

Besides liposomes, micelles are lipid-based preparations in the nanometer range that were found to be useful for drug-delivery applications. Micelles are colloidal aggregates of surfactants when dispersed in an aqueous solution. Micelles are different from liposomes in that they are monolayered and hence smaller in size. Micelles have recently been used for the delivery of drugs, foreign genes in gene-therapy procedures for cancer, and genetic disorders. Micellar formation occurs due to solvation at a threshold called critical micelle concentration (CMC), ${ }^{22}$ which is the concentration of the surfactants above which micelles are shaped. Micelles have recently been applied in oncology by designing nanoscale formulations that are capable of carrying anticancer agents and/or delivery of tumor-suppressive genes. Micelle formation is affected by various factors such as concentration of the surfactant, temperature, $\mathrm{pH}$, and ionic strength. Micelles show increased efficacy in targeting cancer as compared to free or uncoated drug by virtue of their EPR effect and reduced opsonization by surface conjugation with polymers. Because micelles are formed due to the monolayer association of surfactants, such molecules can only contain one kind of anticancer drug at a time, being hydrophobic. Micelles can thus be an advantage in cases of administration of one kind of hydrophobic anticancer drug such as the taxol family. Thus, micelles are yet another type of nanosomal preparation formed with a unilayer of a surfactant (ordinarily phospholipid) useful in gene therapy, and delivery of hydrophobic drugs for cancer therapeutics.

In one of the earliest studies that reported the synthesis of PEG-phosphatidylethanolamine (PE) micelles contained the hydrophobic drug paclitaxel. Immunomicelles were designed with PEG-PE and possess stealth and tumortargeting properties. While PEG confers the stealth, the $\mathrm{mAb}$ incorporated in the corona of the micelle bestow its tumor-targeting property. In addition to this, the immunomicelle constructed was radiolabeled with ${ }^{111}$ In for quantifying the uptake and imaging the target site. These novel immunomicelles developed by Torchilin's group had a unique tumor cell nucleosome-recognizing antibody, specific 
to tumor cells. ${ }^{23}$ The lipid content of the micelle made it possible to accommodate sparsely soluble anticancer drugs like taxol. The immunomicelles, when tested on a mouse Lewis lung carcinoma model, showed improved tumor inhibition compared with free taxol. Immunomicelles that carry ligands against specific tumor antigens embedding the hydrophobic drug within its lipid bilayer can thus increase drug biodistribution. Owing to their poor solubility, drugs like taxol have a very low therapeutic index, but when delivered using such nanosystems, they demonstrate better efficacy and low nontarget toxicity. ${ }^{23,24}$ Micelles also show highlighted advantages over liposomes in several points. Firstly, micelles are smaller in size than the liposomes that ensure better uptake at tumor sites. ${ }^{23}$ Liposomes require optimum orientation for their successful localization within the tumor interstitium and take advantage of the leaky vasculature and diminished number of lymphatics whereas micelles show smooth and easier accumulation in the target site and do not have such constraints. Liposomes and micelles are synthesized from simple lipids and have their own advantages and limitations among the alternative preparations for drug-delivery polymer formulations being explored by several groups worldwide.

\section{Synthetic copolymers for drug and siRNA nanoformulations}

Polymeric formulations for drug delivery have been in vogue for a long time, but their potential in this arena has been hampered by stability and biocompatibility. Nevertheless, several groups have developed unique polymer formulations to address these issues. Polymer formulations of chemotherapeutic drugs have certain advantages such as increased solubility, prolonged duration of exposure, selective delivery of entrapped drug to the site of action, improved therapeutic index, and they potentially overcome resistance associated with the parent drug. Among the long list of polymeric formulations, several research groups have explored poly(cyanoacrylate) and poly(lactic acid)-based preparations extensively due to their improved biocompatibility and biodegradability. We will briefly discuss pertinent approaches using these formulations.

Amphiphilic copolymers are composed of hydrophilic and lipophilic moieties. Poly(alkyl cyanoacrylate) (PACA) NPs are amphiphilic copolymers that were first developed 25 years ago by anionic polymerization of alkyl cyanoacrylate in the presence of dextran. PACA NPs are made of polymers that undergo in vivo degradation and have good biocompatibility. Various types of PACA NPs have been designed including nanospheres and oil- and water-containing nanocapsules. These NPs made possible the in vivo delivery of many different types of drugs including those presenting seriously challenging delivery problems. ${ }^{25}$

Ambruosi and colleagues investigated the biodistribution in the brain and body of tumor-bearing mice, ${ }^{14} \mathrm{C}$ labeled, doxorubicin-loaded poly(butyl-2-cyanoacrylate) NPs and polysorbate-80 (P-80)-coated poly(butyl-2-cyanoacrylate) NPs. ${ }^{26}$ The study showed that the polysorbate coating of NPs prevented their uptake by the reticuloendothelial cells and the drug-loaded particles also showed uptake in the intracranially implanted glioblastoma cells, crossing the blood-brain barrier. Another study from the same group determined the influence of surfactants, polymer, and doxorubicin-loading on the antitumor effect of poly(butyl cyanoacrylate) NPs in a rat glioma model. ${ }^{27}$ The NPs were coated with different surfactants and injected intravenously on days 2, 5, and 8 after intracranial implantation of glioblastoma to rats. Thirty-five percent of tumor-bearing animals treated with the poly( $N$-butyl cyanoacrylate) doxorubicin-loaded NPs coated with P-80 survived for over 180 days while animals treated with other NP preparations had lower survival times. The authors concluded that the difference in antitumoral efficacy could be attributed to the variable behavior of NP formulations, their surface charge, and their interaction with blood and the EPR effect. $^{27}$

Brigger and colleagues evaluated the preclinical efficacy of PEG-coated poly(hexadecyl)cyanoacrylate (PEGPHDCA) nanospheres loaded with doxorubicin, which as an unpacked drug, has poor distribution in the central nervous system. ${ }^{28}$ PEG-PHDCA nanospheres showed preferential accumulation in the intracranially implanted brain tumor cells. These nanospheres overcame multidrug resistance and performed better than the commercially available Caelyx ${ }^{\circledR}$ (Janssen-Cilag Ltd, Buckinghamshire, UK), the stealth liposomal preparation of doxorubicin. A later study by the same group, which used the same polyacrylate nanoparticulate preparations, interrogated the preclinical efficacy of the free and nanosphere-encapsulated doxorubicin in $9 \mathrm{~L}$ gliosarcoma tumor models. ${ }^{29}$ The study showed that the doxorubicinloaded nanospheres accumulated more in lungs and spleen and has been attributed to binding of plasma proteins to the charged nanosphere surfaces. Despite this nonspecific accumulation of doxorubicin-loaded nanospheres, the $9 \mathrm{~L}$ tumor-bearing animals showed a higher maximum tolerated dose to the nanospheres as compared to the free drug.

In a recent study, curcumin-loaded poly(butyl cyanoacrylate) NPs coated with chitosan were prepared by 
emulsion polymerization. ${ }^{30}$ The particles thus prepared had spherical morphology and exhibited similar cytotoxicity to native curcumin against three human carcinoma cell lines. The authors also showed that the unloaded cyanoacrylate NPs did not show any toxicity to the cell lines. The study also showed that the curcumin-loaded cyanoacrylate particles decreased the levels of angiogenic stimulants, namely vascular endothelial growth factor and cyclooxygenase-2. Besides, the curcuminloaded particles could inhibit the hepatocellular xenografts in mice. A significant aspect in this study is that curcumin encapsulation in the poly(butyl cyanoacrylate) NPs showed an altered pharmacokinetic profile as compared to native curcumin. This study is important, since it is well known that native unpacked curcumin has good anticancer potency when tested on in vitro conditions, whereas it has reduced bioavailability under in vivo conditions. Thus NP preparation has been effective in delivering the drug at target site without compromise.

In a recent study, a naturally occurring apolipoprotein was used as a targeting ligand for poly(butyl cyanoacrylate) NPs loaded with curcumin. ${ }^{31}$ The ApoE3-labeled NPs showed preferential accumulation by receptor-mediated endocytosis and also inhibited beta-amyloid-induced cytotoxicity in neuroblastoma cells. These studies are important in that natural products with proven anticancer activity packed in a NP formulation have a better bioavailability profile and potential as useful agents for further research. This is because natural products like curcumin have the least or very low normal cell toxicity. Tamoxifen-loaded poly(MePEGcyanoacrylate-co-hexadecylcyanoacrylate) nanospheres were synthesized and characterized by Brigger and colleagues. ${ }^{32}$ Tamoxifen encapsulated in nanospheres showed transcription inhibitory activity in ex vivo experiments.

Gemcitabine is a rapidly metabolized anticancer drug. To protect the drug, Stella and colleagues covalently coupled an acyl chain and this lipophilic derivative was encapsulated using poly(H(2)NPEGCA-co-HDCA) nanospheres and nanocapsules. ${ }^{33}$ Their cytotoxicity was tested on two human cancer cell lines and compared with the cytotoxicity of gemcitabine and free 4-(N)-stearoylgemcitabine.

Several research groups are actively working on NP-based systems for chemotherapeutic drug delivery to bring about effective tumor regression. Some groups are involved in development of cancer biotherapy involving activation of the cell's own machinery to achieve regression. Among such biotherapy efforts, RNA interference (RNAi) is one such strategy. siRNAs are biomolecules that effectively utilize the cell's own enzymatic machinery to break down or regulate the mRNA levels of key proteins. Effective tumor regression can be achieved by sequencing siRNAs to silence genes or the proteins implicated in tumorigenesis. Though RNAi technology is just about a decade old, several clinical trials are in progress for assessing its therapeutic potential. The success of this technology is limited by several factors, which include stability of siRNA, inability to cross biological membranes, and off-target effects. Hence there are concerted efforts to develop a suitable carrier for effective, specific delivery of siRNA. In an interesting study by Toub and colleagues, siRNA against EWS-Fli1 fusion gene for oncogenic transcription factor, was encapsulated in a poly(isobutyl cyanoacrylate) aqueous core nanocapsule and delivered to NIH/3T3 cells ectopically expressing the Ewing's sarcoma fusion gene. ${ }^{34}$ Studies of the intracellular penetration by confocal microscopy showed that nanocapsules improved the intracellular penetration of siRNA with mainly cytoplasmic localization. These biodegradable siRNA-loaded nanocapsules were then tested in vivo on EWS-Fli1-expressing mice tumor xenograft and were found to trigger a dose-dependent inhibition of tumor growth after intratumoral injection. A specific inhibition of EWS-Fli1 was also observed. This study showed that the alkylcyanoacrylate NPs could serve as versatile carriers of different therapeutic disposition inclusive of drugs and therapeutic biomolecules like the siRNA. A notable drawback in this study is the intratumoral administration of the nanoformulation. This approach does not allow for the evaluation of such nanomaterials with therapeutic biomolecules in the systemic circulation.

\section{Current status of nanomaterial-based drug-delivery systems}

Nanotherapeutics are rapidly progressing and are being implemented to solve several limitations of conventional drug-delivery systems such as nonspecific biodistribution and targeting, lack of water solubility, poor oral bioavailability, and low therapeutic indices. Several stability and drug payload studies on the NP formulations have shown that they are highly stable with high carrier capacity, are feasible for incorporation of both hydrophilic and hydrophobic substances, and can be administered by various routes, including oral application and inhalation. ${ }^{35,36}$

NPs have been designed for optimal size and surface characteristics to increase their circulation time in the bloodstream and their biodistribution. They are also able to carry their loaded active drugs to cancer cells by selectively using the unique pathophysiology of tumors, such as their enhanced permeability and retention effect and the tumor microenvironment. A number of NP-based drugs have been 
approved for treatment of a variety of chronic diseases including cancer. Table 1 gives a list of such clinically approved NP systems and their indications. NP-based drugs like Emend ${ }^{\mathbb{B}}$ (Merck Sharp \& Dohme Ltd, Herts, UK) and TriCor ${ }^{\circledR}$ (Abbott Laboratories, North Chicago, IL) have been approved for the suppression of chemotherapy-induced nausea and vomiting and to reduce cholesterol. In 1996, the first NP-based drug, DaunoXome $^{\circledR}$ (Gilead Sciences, Cambridge, UK), was approved by the US Food and Drug Administration for the treatment of Kaposi's sarcoma. Multifunctional and multiplex NPs are now being actively investigated and are on the horizon as the next generation of NPs for personalized and tailored cancer treatment.

Nanomaterial-based drug-delivery systems synthesized from any starting materials like the lipid-based liposomal or the cyanoacrylate-based formulations have been tested in several models and have been shown to be useful for drug delivery. A limited number of these preparations are also used in the clinics for treatment of malignant diseases. Nevertheless, despite their acceptable therapeutic load delivery, these systems suffer from disadvantages like biocompatibility and lack of target specificity. The need for development of targeted drug delivery using nanoformulations has gained importance and is now taking a lead role. Many targets are being discovered through the application of genomic and proteomic technologies. Thus there is plenty of room to improvise these systems to address the above-mentioned issues and several groups including ours are working to improve the targeting properties of NPs and for the development of targeted therapeutics. In the following section we will discuss the current research in development of targeted drug-delivery systems.

\section{Introduction to targeted drug delivery}

A promising strategy to achieve direct drug delivery is the development of active targeting of cancer cells through interactions mediated by ligands such as antibodies, lectins, aptamers, folate, and peptides as presented with NPs. Active tumor-targeting of NPs may be achieved with either direct targeting or the pretargeting multistep method. In direct targeting, NPs could be covalently coupled with the ligand and the resulting drug carrier be administered at once. In the pretargeting approach, the therapeutic molecule is not coupled with the ligand and is administered after an appropriate delay following the targeting ligand. This delay allows time for the antibody to localize and concentrate in the tumor. Commonly, pretargeting protocol involves an avidin-biotin system or bispecific antibodies.

\section{Models for targeted drug delivery Anti-HER2 antibody-labeled NPs}

Antibody-labeled NP is one of the most coveted modes of active targeting of NPs. mAb is currently a solitary therapeutic option in clinics as a form of immunotherapy for cancer targeting of the aberrantly upregulated cell surface receptors pivotal in tumor cell proliferation, motility, and metastasis. Thus blocking the activity of the upregulated receptor by

Table I Clinically approved nanoparticle systems and their indication

\begin{tabular}{|c|c|c|c|c|c|}
\hline Compound & Nature & Trade name & Indication & Status & Year of approval \\
\hline $\begin{array}{l}\text { Liposomal } \\
\text { daunorubicin }\end{array}$ & Liposome-drug conjugate & DaunoXome & Kaposi's sarcoma & Approved & 1996 \\
\hline Rapamycin & Antibiotic & Rapamune & $\begin{array}{l}\text { Antiproliferative agent } \\
\text { in colorectal cancer }\end{array}$ & Approved & 1999 \\
\hline $\begin{array}{l}\text { Liposomal } \\
\text { vincristine }\end{array}$ & Liposome-drug conjugate & OncoTCS & Non-Hodgkin's lymphoma & Approved & 2004 \\
\hline $\begin{array}{l}\text { Liposomal } \\
\text { doxorubicin }\end{array}$ & Liposome-drug conjugate & Myocet & $\begin{array}{l}\text { Metastatic breast cancer } \\
\text { in combination with } \\
\text { cyclophosphamide }\end{array}$ & $\begin{array}{l}\text { Approved } \\
\text { (Europe) }\end{array}$ & 2005 \\
\hline $\begin{array}{l}\text { Stealth liposomal } \\
\text { doxorubicin }\end{array}$ & Liposome-drug conjugate & Doxil/Caelyx & $\begin{array}{l}\text { Kaposi's sarcoma, refractory } \\
\text { ovarian and breast cancer }\end{array}$ & Approved & 2005 \\
\hline Albumin-paclitaxel & Albumin-drug conjugate & Abraxane/ABI-007 & Metastatic breast cancer & Approved & 2005 \\
\hline Megesterol acetate & Hormone & Megace & Breast and endometrial cancer & Approved & 2005 \\
\hline Fenofibrate & Hypolipidemic agents & TriCor & Reduction of cholesterol & Approved & 2005 \\
\hline PEG-L-asparaginase & PEG-enzyme conjugate & Oncaspar & Leukemia & Approved & 2006 \\
\hline Nanopaclitaxel & Mitotic inhibitor & Nanoxel & Breast cancer & Approved & 2007 \\
\hline Aprepitant & NKI receptor antagonist & Emend & $\begin{array}{l}\text { Suppression of chemotherapy- } \\
\text { induced nausea and vomiting }\end{array}$ & Approved & 2008 \\
\hline
\end{tabular}

Abbreviation: PEG, poly(ethylene glycol). 
binding it with a ligand (such as mAb represented on the nanovector) would ensure arrest of the signaling pathway(s). $\mathrm{mAb}$ are thus useful in recognition of cell surface antigens commonly dysregulated in cancers, for instance RTKs like EGFR/HER2. HER2 is an oncogene and its upregulation is manifested in several malignancies such as breast, ovarian, endometrial, and stomach cancers and is thus a thoroughly studied model for cancer therapy. Figure 4 explains the concept of antibody-targeted drug delivery as a model for active targeting. In a study by Nobs and colleagues, two approaches were attempted for targeted delivery of biodegradable poly(lactic acid) NPs to tumor cells. ${ }^{37}$ Anti-HER2 mAbs (trastuzumab; Herceptin ${ }^{\circledR}$ [Roche Products Ltd, Herts, $\mathrm{UK}]$ ) and anti-CD20 mAbs (rituximab; Mabthera ${ }^{\circledR}$ [Roche Products Ltd]) were used as targeting ligands. Two cell lines were used, SKOV-3 human ovarian cancer cells expressing HER2 antigen, and Daudi lymphoma cells, expressing CD20 antigen. On each cell line, the antibody directed against the nonexpressed antigen served as isotype-matched irrelevant control Ig. In the direct approach, NPs exposing mAbs at their surface were incubated with the two tumor cell lines. In the pretargeting protocol, tumor cells were pretargeted with biotinylated $\mathrm{mAbs}$ before the administration of avidin-labeled NPs. The cell interactions of fluorescence-labeled NPs were measured by flow cytometry. The analysis showed that the targeted NPs accumulated in antigen-positive cells compared to nontargeted NPs.

Park and colleagues studied the pharmacokinetics and therapeutic efficacy of anti-HER2 immunoliposomes containing doxorubicin in animal models and showed that anti-HER2 immunoliposome-doxorubicin showed superior therapeutic benefits compared with combinations consisting of free Herceptin MAb plus free doxorubicin or free MAb plus liposomal doxorubicin. ${ }^{38}$ This study concluded that anti-HER2 immunoliposomes produced enhanced antitumor efficacy via targeted delivery.

Sun and colleagues synthesized poly(D,L-lactide-coglycolide)/montmorillonite (PLGA/MMT) NPs, which were decorated with HER2 antibody trastuzumab for targeted breast cancer chemotherapy with paclitaxel as a model anticancer drug. ${ }^{39}$ Therapeutic studies using these NPs showed that the efficacy of the drug formulated in the NPs with surface decoration could be 12.74 times higher than that of the bare NPs and 13.11 times higher than taxol.

Gold-gold sulfide NPs when exposed to a pulsed nearinfrared resonant laser exhibit photoluminescence that can be utilized to visualize cancerous cells in vitro. When these NPs are conjugated with anti-HER2 antibodies there is a specific binding to SK-B3 breast cancer cells where HER2 receptor is overexpressed enabling precise imaging of the cancerous cells. When a higher excitation power was employed, thermal damage leading to cancer cell death was also observed. ${ }^{40}$

\section{Apolipoprotein-labeled NPs}

Apolipoproteins are carrier proteins that combine with lipids to form lipoprotein particles, that have hydrophobic ligands at the core and hydrophilic side chains made of amino acids. These lipoproteins are metabolized in liver and muscles through receptor-mediated endocytocis, recognized by the apoproteins in the complex. Thus apoproteins give an address for the lipoprotein to be taken up by specific receptors. The fact that apoproteins act as homing ligands prompted researchers to use that as a targeting label for NPs. Recently lipoproteins have come to the attention of oncologists with the realization that high-density lipoproteins (HDL) show increased uptake by tumor cells and in turn Effect cell proliferation. This is made possible as a consequence of the overexpression of the HDL receptor, scavenger receptor $\mathrm{B} 1$ (SR-B1). ${ }^{41}$ The receptor has been shown to be expressed in normal cells like that of liver cells, but reports have indicated gross upregulation of SR-B1 in tumor cells to concentrate HDL required for active cellular proliferation involving the STAT3 and FAK pathways.

Efforts have thus been made in the synthesis of targeted HDL NPs that can betray a tumor cell in uptake of HDL, thus loading the anticancer agent driving the tumor mass to direct cell killing. A group of scientists has reported an elaborate and unprecedented study on delivering siRNA tagged with synthetic reconstituted HDL (rHDL) NPs. ${ }^{41}$ The study was initiated with synthesis of siRNA surface tagged with HDL molecules and their characterization using transmission electron microscopy followed by in vitro studies on human cancer cell lines. In vitro cell line studies showed effective silencing of the target mRNAs. The rHDL loaded with the siRNAs was also tested and found to be effective on nude mice bearing ovarian xenografts.

\section{Peptide-labeled NPs}

Peptide labeling of NPs is steadily gaining importance in cancer research. It can be employed to target drug conjugated NPs into specific cancer cells as they can be based on ligands associated with receptors on specific cells/organs/tumor cells themselves or tumor-support structures such as stroma or neovasculature. Peptides can also be used as structural building blocks of the NPs themselves. Peptide-labeled NPs can be used in the imaging of tumor cells and tumor tissue. Fluorescent silica NPs (FSiNPs) coupled with a molecular 


\section{Active targeting mechanism for nanoparticle}

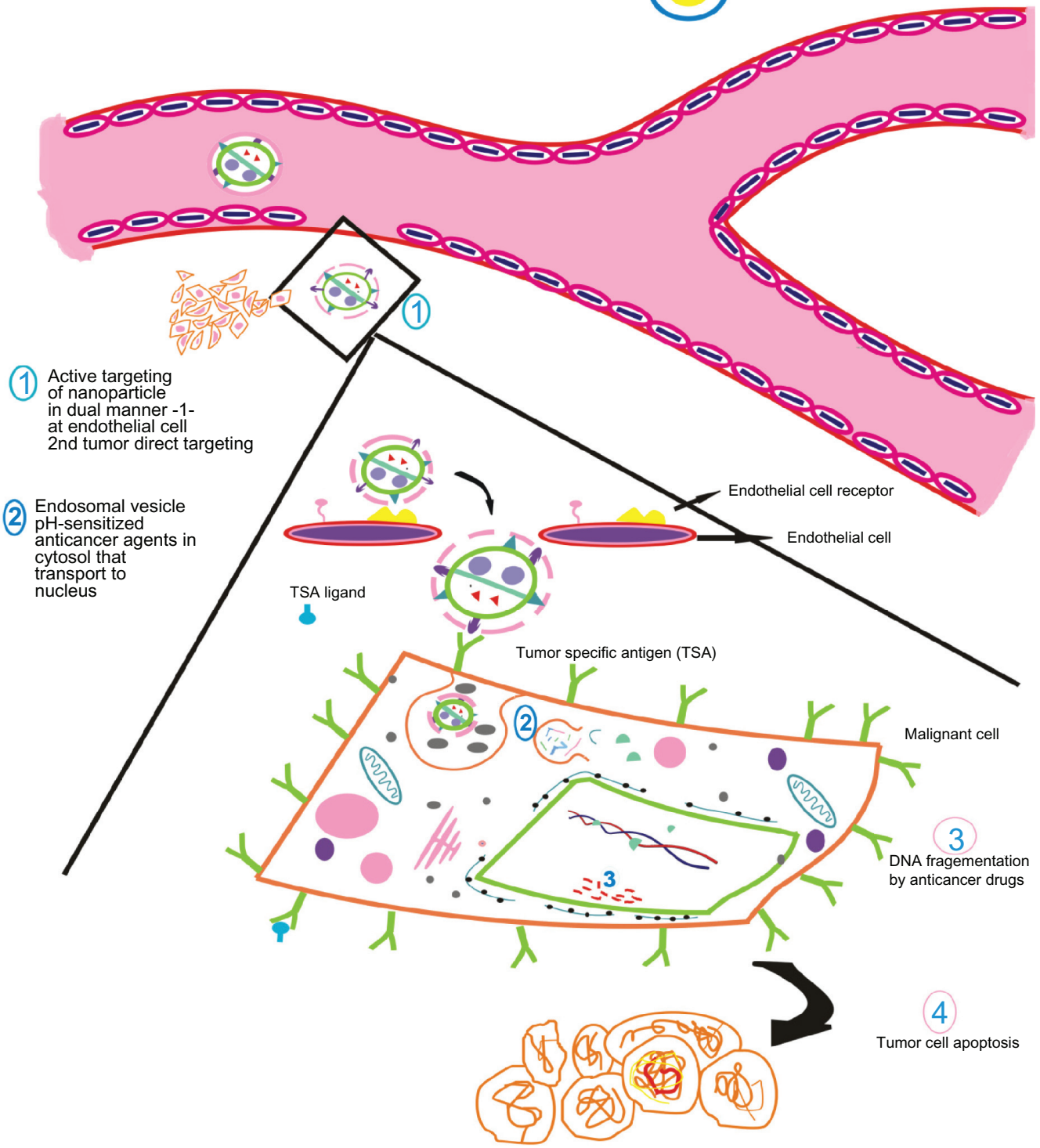

Figure 4 Active targeting of nanoparticles to tumor cells according to the presence of tumor-seeking addresses on nanoparticle surface promoting tumor residence. Active nanoparticle targeting: the nanoparticle is surface tagged with a certain ligand against a tumor-specific antigen. This enables direct targeting to target site. The model here discusses dual targeting effected in a synergistic fashion: targeting endothelial cell receptors (vascular cellular adhesion molecules, vascular endothelial growth factor, etc) such as angiogenesis antagonists and monoclonal antibodies against typical tumor signatures such as endothelial growth factor receptors, HER2, which result in tumor cell apoptosis. Endothelial cell targeting curbs angiogenesis of tumor interstitium preventing oxygen supply and nutrients while tumor targeting causes direct cell killing as the nanoparticle encapsulating the anticancer drug is taken up by the cell. (I) The nanoparticle is targeted against endothelial cell receptor and against a tumor antigen. (2) The nanoparticle is taken up by the tumor cell via endocytosis wherein nanocarrier vesicles formed release the contents in a pH-dependent manner. The anticancer drug(s) embedded in the nanovector is(are) released and translocated to the nucleus. (3) Action of anticancer drug results in DNA fragmentation that finally leads to (4) programmed cell death.

recognition element allows for effective in vitro and ex vivo imaging of tumor cells and tissues. A study reported the targeting and imaging of MDA-MB-231 human breast cancer cells using arginine-glycine-aspartic acid (RGD) peptide-labeled FSiNPs; the FSiNPs exhibited high target binding to alpha(5)beta(3) integrin receptor (ABIR)-positive MDA-MB-231 breast cancer cells in vitro. ${ }^{42}$ High integrin alpha(5)beta(3) expression level of the MDA-MB-231 tumors was clearly visible due to the special targeting effects of the RGD peptide-labeled FSiNPs. 
Peptide-labeled NPs may also be used for targeted gene silencing. A study shows that RGD-CH-NP is a novel and highly selective delivery system for siRNA with the potential for broad applications in human disease.$^{43} \mathrm{RGD}$ peptide conjugated with chitosan by thiolation reaction was confirmed by proton-nuclear magnetic resonance (H-NMR). Binding of RGD-CH-NP with alpha(5)beta(3) integrin was examined by flow cytometry and fluorescence microscopy. Antitumor efficacy was examined in orthotopic mouse models of ovarian carcinoma. This approach resulted in significant inhibition of tumor growth compared with controls.

\section{Aptamer-labeled NPs}

Aptamers are DNA or RNA oligonucleotides that, through intramolecular interactions, fold into unique tertiary conformations capable of binding to target proteins with high affinity and specificity. This property makes them an attractive class of targeting molecules as they are also nonimmunogenic and exhibit remarkable stability and are often referred as chemical antibodies. Docetaxel (Dtxl)-encapsulated NP, with PLGA-b-PEG copolymer and surface fluoropyrimidine RNA aptamers, has been reported to recognize the extracellular domain of prostate-specific antigen (PSMA) which is a well recognized antigen on the surface of prostate cancer cells. They bind and are taken up by the cells resulting in a significantly enhanced in vitro cellular toxicity as compared with nontargeted NP lacking PSMA, which demonstrates its therapeutic potential. ${ }^{44}$

\section{Folate-linked NPs}

Folic acid, a member of the B complex group of vitamins, is an important co-factor in one-carbon transfer reactions for biosynthesis of nucleotides and plays a key role in DNA and RNA synthesis, epigenetic processes, cellular proliferation, and survival. Three distinct transporters mediate cellular folate uptake. Among them, the folate transporter named as the folate receptor (FR), often referred to as the high affinity folate-binding protein, is a cell surface glycosylphophatidylinositol (GPI)-anchored glycopeptide that characteristically binds folic acid and transports it by a nonclassical endocytic mechanism. ${ }^{45-47} \mathrm{~A}$ wide range of chemical conjugates of folic acid, antifolate drugs, and immunological agents have been used for developing therapeutic and imaging agents for various diseases. Studies have shown a significant correlation between FR alpha expression and the grade and differentiation status of the tumor, thus poorly differentiated and aggressive tumors express high levels of FR alpha. ${ }^{48}$
Folic acid is known to mediate intracellular NP uptake. ${ }^{49}$ Folic acid is coupled with human serum albumin (HSA) NPs through carbodiimide reaction resulting in the formation of HSA-NPs spheres. The cellular binding and uptake was studied in normal foreskin fibroblasts (HFF), human neuroblastoma cells UKF-NB3, and in rat glioblastoma cell lines. An increased NP uptake was observed in cancer cells, but not in normal HFFs. This suggests its application in targeted tumor drug delivery.

Folate-linked NPs can also be used in tumor imaging and radiotherapy. In a recent study, folate-conjugated shell cross-linked NPs (SCKs) were functionalized with folate, fluorescein thiosemicarbazide (FTSC), and TETA. ${ }^{50}$ SCKs were obtained by cross-linking the shell of micelles obtained from amphiphilic diblock copolymers. It was investigated on $\mathrm{KB}$ cells and evaluated in athymic mice bearing small-size $\mathrm{KB}$ cell xenografts. The specific interaction of FTSC-SCKfolate with the FR in vitro was confirmed. The evaluated ${ }^{64}$ $\mathrm{Cu}$-labeled SCKs exhibited long circulation in blood and were able to passively accumulate in tumors.

In case of cancers like colorectal carcinoma, where early detection can significantly improve mortality, an alginatecomplexed folate chitosan NP has been reported for photodynamic detection. These NPs are readily engulfed by the cancer cells through folate receptor-mediated endocytosis. When they are loaded with 5-aminolevulinic acid (5-ALA) an improved release in the cellular lysosome was observed hinting at an excellent vector for colorectal-specific delivery of 5-ALA for fluorescent endoscopic detection. ${ }^{51}$

Folate-conjugated liposomes showed minimal nonspecific adsorption to serum proteins. Folate-PEG-liposome loaded with doxorubicin showed a 45-fold higher uptake in FR-rich $\mathrm{KB}$ cells compared to nontargeted liposomal-doxorubicin and 86 -fold greater cytotoxicity. In mice bearing $\mathrm{KB}$ cell tumor xenografts, treatment with folate-targeted liposomal doxorubicin produced a $31 \%$ inhibition of tumor growth. ${ }^{52}$ Another study using a multidrug-resistant M109R cell line overexpressing FR showed that the liposomal doxorubicin was taken up despite a functional drug efflux pump operating in the cells. This preparation had a 10 -fold higher cytotoxicity compared with control groups treated with nontargeted liposomes. Magnetic resonance imaging of mice bearing subcutaneous KB tumors showed that superparamagnetic iron oxide (SPIO) NPs were rapidly internalized in vivo by the tumor cells only when conjugated with folate. ${ }^{53,54}$

Tumor-targeted drug delivery systems are currently envisioned as magic bullets for cancer therapy and several groups are working globally for development of robust 
systems addressing issues of specificity. A summary of a few important nanovector prototypes against typical tumor signatures is presented in Table 2 .

\section{Concept of multifunctional NPs}

Nanoscale formulations for oncology have overcome the demerits associated with chemotherapeutic pharmaceuticals such as specificity, toxicity, biodistribution to target site, elimination, and excretion. NPs are thus biodegradable materials that contain the anticancer agent within it. Their nanometer sizes enable efficient uptake at the tumor site by their enhanced permeability and retention effect. We suggest a model for multifunctional NPs (Figure 5) that acts as a drug-delivery system as well as a diagnostic agent. With the concept of combination chemotherapy in practice, it is useful to deliver two different drugs of varying mechanisms of action in a single delivery vehicle. With this objective, the system could be designed to epitomize two anticancer drugs, drug 1 and drug 2, that are separated from each other via an emulsion column. Specifically, the anticancer agents are dissolved in separate matrices based on their solubility, whether lipophillic or hydrophilic. In addition, the model illustrates a stimulus-dependent release of the pharmaceuticals. This is based on the concept that chemotherapeutic agents administered as prodrug only get metabolized into active form under suitable conditions, ideally present in the tumor interstitium. Thus the stimuli (such as oxygen pressure or $\mathrm{pH})$ acts as a catalyst to cause the release of anticancer agent(s) particularly at the target site. On the exterior, the presence of a cell-penetrating peptide facilitates the cellular entry of the nanomaterial. When a nanomaterial has the above-mentioned components, the targeting to tumor site is passive, while engineering ligands to tumor specific antigens would ensure more specific uptake to the tumor site, a phenomenon known as active targeting. In our model, we suggest dual targeting: one against the endothelial cell receptor and a second against the tumor marker. Endothelial cell targeting is a novel strategy to curb angiogenesis by sequestering receptors such as vascular cellular adhesion molecules, selectins, and vascular endothelial growth factor receptors that have been documented to be associated with tumor angiogenesis. In addition, antiangiogenic therapyenabled tumor killing has been conceived through several pharmacologic means. In this regard, developing agents that antagonize the angiogenic property of endothelial cells would enable reduced tumor growth by strategically cutting oxygen and nutrient supply to the tumor interstitium. ${ }^{62}$ A study conducted by Jain reported that herceptin, the $\mathrm{mAb}$ against the cell surface receptor HER2, has antiangiogenic properties by normalizing the tumor vasculature in a mice model. ${ }^{63}$ It is known that malignancies arise due to gross mutations attributable to upregulation of certain proteins that become the signatures of various cancers (these include HER2, PSA, EGFR). Monoclonal antibodies targeted against these tumor markers enable direct tumor targeting to tumor site leaving the normal cells unharmed, thus significantly reducing cytotoxicity. The strategy is to cut oxygen and nutrient supply to the tumor cells. A polymer like PEG is included to ensure

Table 2 Important nanovector paradigms against typical tumor signatures

\begin{tabular}{|c|c|c|c|c|c|}
\hline Target & Animal model & Nanoparticle used & $\begin{array}{l}\text { Hallmark } \\
\text { targeted }\end{array}$ & Target ligand & Reference \\
\hline VEGFR-2 & BALB/c (4TI xenografts) & Boronated dendrimers & Angiogenesis & VEGF analogue & Backer et al ${ }^{55}$ \\
\hline VEGF & $\begin{array}{l}\text { Nude mice (KI } 735-\mathrm{M} 2 \\
\text { melanoma and } \mathrm{CT}-26 \text { xenografts) }\end{array}$ & $\begin{array}{l}\text { Dextran magnetic } \\
\text { Nanoparticles conjugated } \\
\text { with } 90 \text { Y-anti-VEGF mAb }\end{array}$ & Angiogenesis & anti-VEGF mAb & Li et $\mathrm{al}^{56}$ \\
\hline$\alpha_{\mathrm{v}} \beta_{3}$ & $\begin{array}{l}\text { Nude mice } \\
\text { (M-2 I L melanoma xenografts) }\end{array}$ & $\begin{array}{l}\text { Cationic nanoparticles } \\
\text { conjugated to integrin } \\
\alpha v \beta 3 \text {-targeting ligand }\end{array}$ & Angiogenesis & RGD mimetics & Hood et $\mathrm{al}^{57}$ \\
\hline VCAM-I & Nude mice (CoLo 677 xenografts) & $\begin{array}{l}\text { VCAM-I targeted } \\
\text { immunoliposomes }\end{array}$ & Angiogenesis & anti-VCAM mAb & Gosk et $\mathrm{al}^{58}$ \\
\hline HER-2 & $\begin{array}{l}\text { Nude mice } \\
\text { (BT-474, MCF-7 xenografts) }\end{array}$ & $\begin{array}{l}\text { Anti-HER-2 Fab' conjugated } \\
\text { PEGylated immunoliposomes }\end{array}$ & $\begin{array}{l}\text { Uncontrolled } \\
\text { cell proliferation }\end{array}$ & $\begin{array}{l}\text { Trastuzumab mAb, } \\
\text { anti-HER-2 Fab' }\end{array}$ & Kirpotin et $\mathrm{al}^{59}$ \\
\hline $\begin{array}{l}\text { Transferrin } \\
\text { receptors }\end{array}$ & NMRI Mice (HT-29 xenografts) & $\begin{array}{l}\text { Transferrin-modified } \\
\text { nanoparticles } \\
\text { containing DNAzymes }\end{array}$ & $\begin{array}{l}\text { Uncontrolled } \\
\text { cell proliferation }\end{array}$ & $\begin{array}{l}\text { Transferrin } \\
\text { Analog }\end{array}$ & Pun et $\mathrm{al}^{60}$ \\
\hline Folate receptor & BALB/c mice J6456-FR xenografts & Folate-targeted liposomes & $\begin{array}{l}\text { Uncontrolled } \\
\text { cell proliferation }\end{array}$ & Folate & $\begin{array}{l}\text { Shmeeda } \\
\text { et } \mathrm{al}^{61}\end{array}$ \\
\hline
\end{tabular}

Abbreviations: VEGFR-2, vascular endothelial growth factor receptor-2; VEGF, vascular endothelial growth factor; $\alpha_{v} \beta_{3}$, alpha5 beta 3 integrin; VCAM-I, vascular cell adhesion molecule I; HER-2, human epidermal growth factor receptor-2; mAb, monoclonal antibody; RGD, arginine, glycine, aspartate; Fab, fragment antigen-binding. 


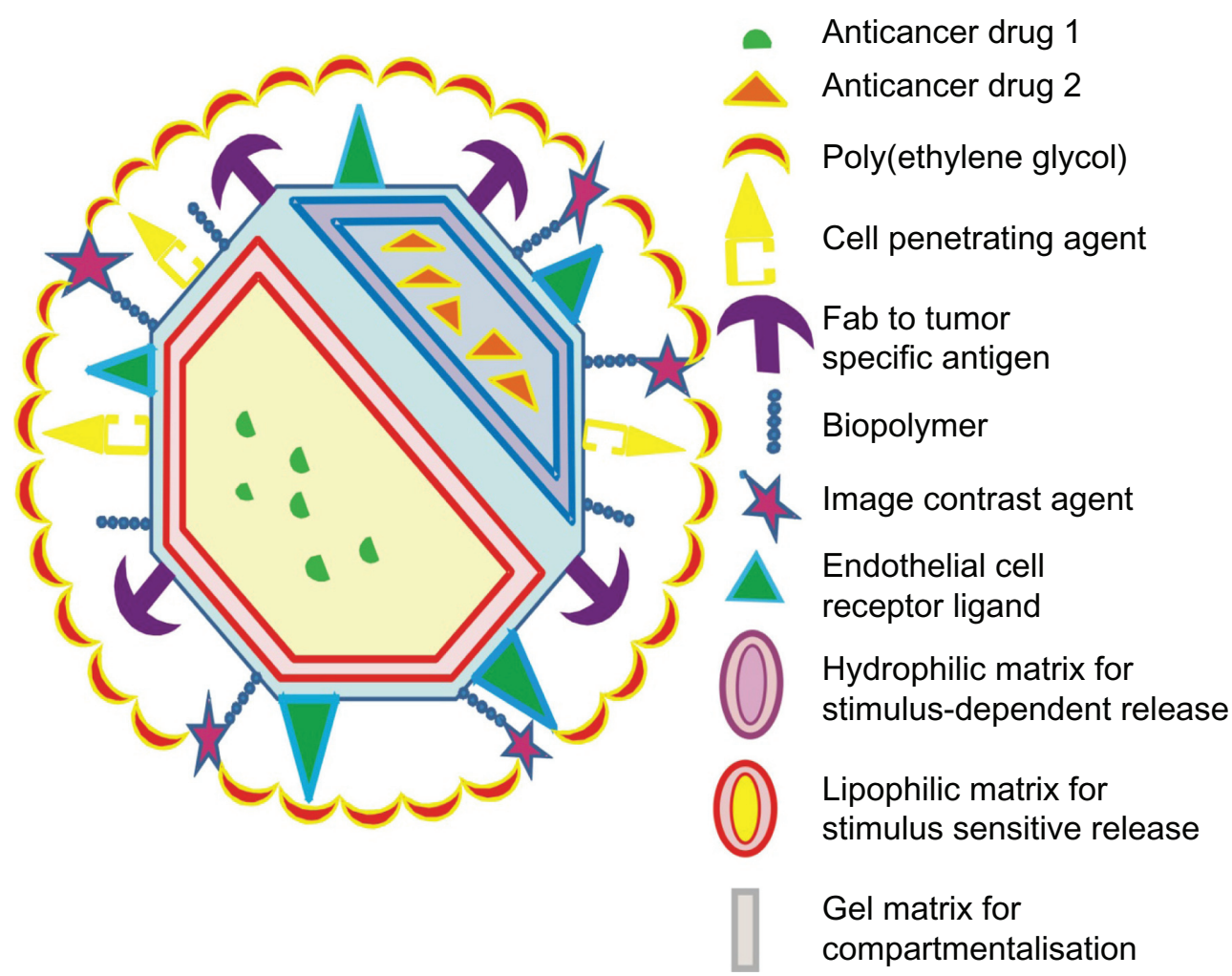

Figure 5 A model for multifunctional nanoparticle with desired characteristics possessing multiple drugs, dual tumor-targeting ligands, cell-penetrating peptide, and imaging agents.

stealth from the reticuloendothelial system so as to enhance bioavailability of the NP. For diagnostic purposes, an image contrast agent may be added to aid in magnetic resonance imaging. NPs engineered for diagnosis would enable early detection of tumor. This would also facilitate timely treatment of the tumor tentatively prior to metastasis.

\section{Multifunctional magnetic NPs for cancer treatment}

Hyperthermia offers an attractive approach for the treatment of cancer because it is associated with fewer side effects in comparison to chemo- and radiotherapy, and it can be used concomitantly with conventional modalities. Various clinical trials have demonstrated the efficacy of such combinations. The first use of magnetic NPs for hyperthermia was reported by Gilchrist in $1957 .{ }^{64}$ Although several potential hyperthermic particles such as silver, lanthanum, and zinc NPs are available, the thermal activation properties of gold NPs, magnetic NPs, and carbon nanotubes have been extensively characterized preclinically and they are furthest along in potential translation to clinical biomedical applications. ${ }^{65}$

Thermotherapy is most efficient for superficial cancers in the form of three modes: local, regional, and whole-body hyperthermia. Local and regional application of hyperthermia can be administered using heat-delivery systems that can dissipate the dose of applied heat at the focused area of cancer. ${ }^{66}$ Radiofrequency ablation is the most commonly used type of local hyperthermia. In this technique, short duration highenergy radio waves are concentrated at the site of the tumor with the aid of a thin needle-like probe via ultrasound guidance capable of emanating high-frequency current resulting in the heating of malignant cells in a minimally invasive fashion without damaging adjacent vital structures. ${ }^{67}$ Three-dimensional phantom models have been developed to mimic tissues. Merkle and colleagues investigated the changes in heat deposition during RF ablation in the presence of SPIO NPs and reported that the temperature along the RF electrode track significantly increased because of the iron content in the polyacrylamide phantom; however, the use of SPIO at physiologic concentrations in rabbit models did not yield significant difference in coagulation diameter. ${ }^{68}$

\section{Augmenting thermal therapy with magnetic NPs}

Thermal therapy can be combined with newer more targeted strategies of tackling cancerous mass, such as nanotechnology or radiotherapy. Magnetic NPs have been studied for their tremendous potential in the diagnosis and treatment of cancer 
and are being increasingly used for clinical applications such as drug delivery, magnetic resonance imaging and magnetic fluid hyperthermia. The concept of using magnetic NPs for drug delivery was proposed by Widder and Senyi in $1978 .{ }^{69}$ All magnetic NPs used so far in vivo are composed of the iron oxides magnetite $\left(\mathrm{Fe}_{3} \mathrm{O}_{4}\right)$ and maghemite $\left(\gamma\right.$ - $\left.\mathrm{Fe}_{2} \mathrm{O}_{3}\right)$ due to their low toxicity and biocompatibilty. ${ }^{70}$ Ferrite NPs are the most sought after, attributable to their physical and chemical properties that are best suited for hyperthermic applications. Two key issues dominate the magnetic properties of NPs: finite-size effects and surface effects which give rise to various special features. Finite-size effects result, for example, from the quantum confinement of the electrons, whereas typical surface effects are related to the symmetry breaking of the crystal structure at the boundary of each particle. Hence, for hyperthermia treatment, particles below $50 \mathrm{~nm}$ in diameter produce the maximum specific absorption rate. ${ }^{71}$ Iron oxide particles with diameters below 30-40 nm are of particular interest because they exhibit superparamagnetic behavior ie, once the magnetic field is removed, they do not retain any magnetization.

\section{Heating cancer with magnetic NPs}

Magnetic NPs can be used as heat-generating systems for therapeutic applications since they generate sufficient heat energy when exposed to an alternating magnetic field (AMF).
These nanometric systems act like a single magnetic domain and hence exhibit the properties of a simple magnetic dipole. ${ }^{64}$ Ivkov et al reported the feasibility of applying high-amplitude AMF to treat cancer tissue with embedded magnetic NPs in 39 female BALB/c athymic nude mice and observed no adverse effects in mice exposed to AMF amplitudes of $\leq 700$ Oe but mice exposed to AMF amplitudes in excess of 950 Oe experienced morbidity and injury. ${ }^{72}$

Preclinical studies on various types of cancer using magnetic hyperthermia have been reported to have promising tumor responses in mouse models. These studies have been pursued independently by different research teams for breast, prostate, and brain tumor models. Clinical trials were conducted in Germany in 59 patients with recurrent glioblastoma multiforme who underwent a combination of intratumoral thermotherapy with low dose radiotherapy of 30 Gy. The thermotherapy was performed using AMF and SPIOs as energy transducer. The results of the study reported a median overall survival of 13.4 months in 59 patients compared to 6.2 months reported from another study using temozolomide as the current standard in the treatment of primary glioblastoma. ${ }^{73}$

\section{Active targeting of magnetic NPs}

Magnetic targeting can be enabled by magnetoliposomes or magnetic polymer particles which can carry active drug

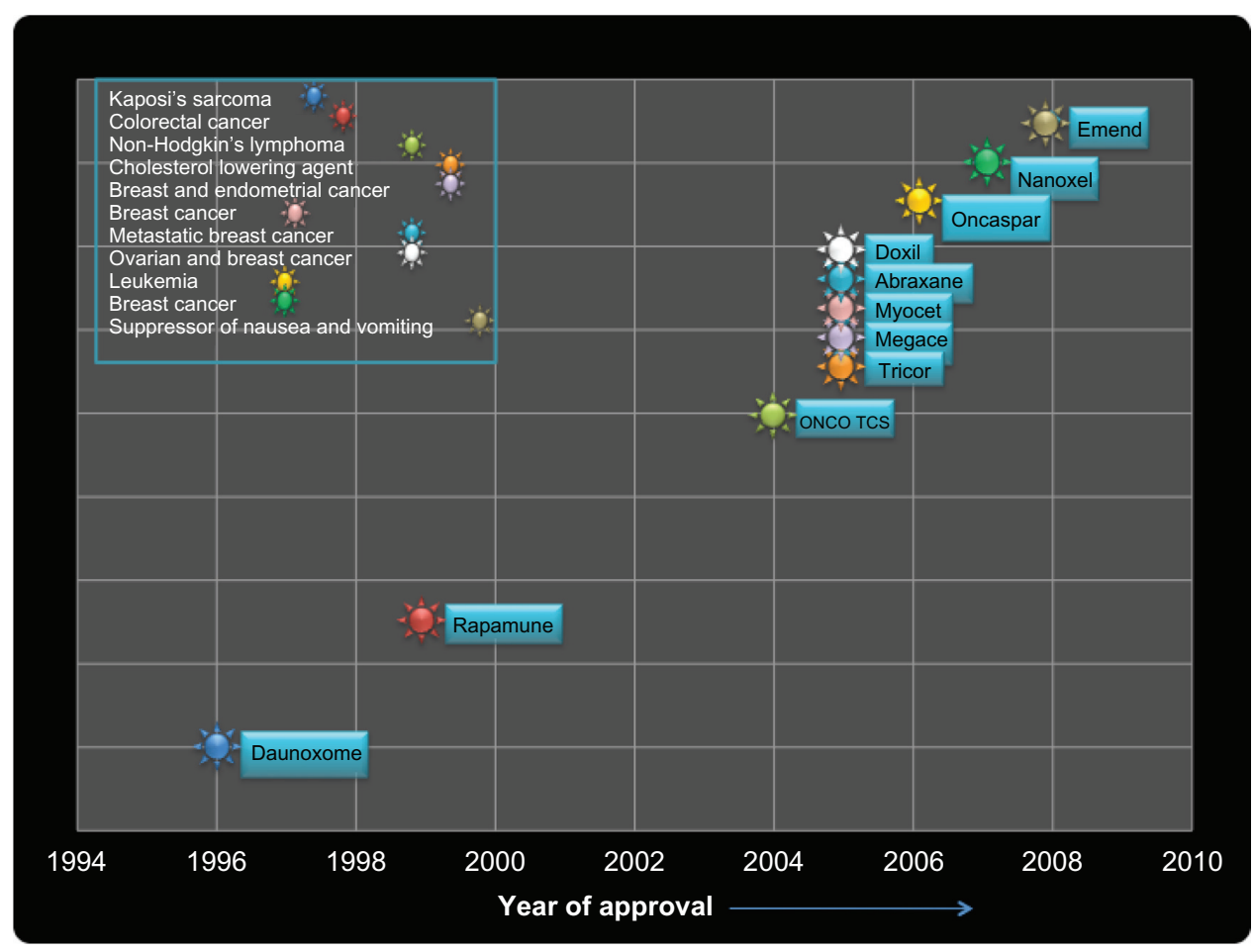

Figure 6 Schematic representation of timelines depicting the clinical approval of nanoparticle-based drug vehicles for human diseases. 
molecules that can be concentrated at a defined target site by local application of an external magnetic field. This can be enabled by surface modification of magnetic NPs where the NPs are conjugated with ligands against suitable molecules overexpressed in tumors. Occhipinti and colleagues synthesized trastuzumab-functionalized PEGylated iron oxide NPs as a model to study the interaction between an mAB nanoconjugate and its receptor (HER2) and have documented the utility of magnetic NPs in designing and testing novel hybrid targeted nanovectors preventively providing a chance to reduce side effects like nonspecific uptake by normal tissues. ${ }^{74}$ Natarajan and colleagues developed multifunctional radioimmunonanoparticles (RINPs) using recombinant antibody fragments, di-scFv-c, for the imaging and therapy of anti-MUC-1-expressing tumors. RINP binding to tumor cells was found to be time-dependent and in vivo uptake was confirmed by pharmacokinetic and whole-body autoradiography in breast cancer mice models. $^{75}$

Magnetic NPs have enormous theranostic application due to their unique and multifunctional properties. Recent advances in materials science allow control of the shape, size, and properties of magnetic NPs with limited toxicity and biodegradability. The challenge lies in designing the "perfect" magnetic NPs combining the different functionalities for greater specificity towards targeted tissues and longer retention time. Such advancements could pave the way for an effective clinical practice.

\section{Conclusion}

Nanotechnology is the manipulation of materials to nanometer scale. The use of nanotechnology has already flourished in various fields such as information and communication. Nanomedicine is a subdiscipline that focuses the advantages of nanotechnology on health care. NP-based drugdelivery systems could be synthesized from a wide panel of startup materials, thus there is plenty of room for innovation in chemical synthesis. The chemist involved in such processes should consult a biologist to learn the application of the materials in medicine and biology, the therapeutic load it can carry, robust laboratory methodology to test the efficacy, target specificity, and most importantly, the biological fate of the materials. It is necessary that both the chemist and biologist discuss the material synthesized for human application with a pharmacologist, the stability of the systems in biological fluids, and efficacy as compared with conventional methods. Thus the emerging field of nanooncology calls for an interplay of expertise from several basic science and clinical departments with the need for testing the nanomaterial-based agents for drug delivery in phase trials in recognized medical centers with good ethical practices. A newly developed nanomaterial-based drug-delivery system has to perform at various levels; only then can it reach its final destination of application to alleviate human ailments. The growing list of approved NPs in medicine (Figure 6) and newer agents in the pipeline present great hopes for our future.

\section{Disclosure}

The authors report no conflicts of interest in this work. The authors wish to acknowledge the support and encouragement of Sri Ramachandra University management and funding from the Government of India, Board of Research in Nuclear Sciences (GV and DP) and Department of Biotechnology (RSK). The authors acknowledge the financial support under the Sri Ramachandra University-Bristol Myers Squib Fellowship scheme (AK and GB).

\section{References}

1. Zamboni WC. Concept and clinical evaluation of carrier-mediated anticancer agents. Oncologist. 2008;13:248-260.

2. Hanahan D, Weinberg RA. The hallmarks of cancer. Cell. 2000;100: 57-70.

3. Byrne JD, Betancourt T, Brannon-Peppas L. Active targeting schemes for nanoparticle systems in cancer therapeutics. Adv Drug Deliv Rev. 2008;60:1615-1626.

4. Puri A, Loomis K, Smith B, et al. Lipid-based nanoparticles as pharmaceutical drug carriers: from concepts to clinic. Crit Rev Ther Drug Carrier Syst. 2009;26:523-580.

5. Immordino ML, Dosio F, Cattel L. Stealth liposomes: review of the basic science, rationale, and clinical applications, existing and potential. Int J Nanomedicine. 2006;1:297-315.

6. McNeil SE. Nanoparticle therapeutics: a personal perspective. Wiley Interdiscip Rev Nanomed Nanobiotechnol. 2009;1:264-271.

7. Burger KN, Staffhorst RW, de Vijlder HC, et al. Nanocapsules: lipid-coated aggregates of cisplatin with high cytotoxicity. Nat Med. 2002;8:81-84.

8. Yuba E, Harada A, Sakanishi Y, Kono K. Carboxylated hyperbranched poly(glycidol)s for preparation of $\mathrm{pH}$-sensitive liposomes. J Control Release. 2011;149:72-80.

9. ElBayoumi TA, Torchilin VP. Tumor-targeted nanomedicines: enhanced antitumor efficacy in vivo of doxorubicin-loaded, long-circulating liposomes modified with cancer-specific monoclonal antibody. Clin Cancer Res. 2009;15:1973-1980.

10. Saad M, Garbuzenko OB, Minko T. Co-delivery of siRNA and an anticancer drug for treatment of multidrug-resistant cancer. Nanomedicine (Lond). 2008;3:761-776.

11. Garg A, Tisdale AW, Haidari E, Kokkoli E. Targeting colon cancer cells using PEGylated liposomes modified with a fibronectin-mimetic peptide. Int J Pharm. 2009;366(1-2):201-210.

12. Strijkers GJ, Kluza E, Van Tilborg GA, et al. Paramagnetic and fluorescent liposomes for target-specific imaging and therapy of tumor angiogenesis. Angiogenesis. 2010;13:161-173.

13. Singh SV, Hu X, Srivastava SK, et al. Mechanism of inhibition of benzo[a]pyrene-induced forestomach cancer in mice by dietary curcumin. Carcinogenesis. 1998;19:1357-1360. 
14. Choudhuri T, Pal S, Das T, Sa G. Curcumin selectively induces apoptosis in deregulated cyclin D1-expressed cells at G2 phase of cell cycle in a p53-dependent manner. J Biol Chem. 2005;280: 20059-20068.

15. Cheng AL, Hsu CH, Lin JK, et al. Phase I clinical trial of curcumin, a chemopreventive agent, in patients with high-risk or pre-malignant lesions. Anticancer Res. 2001;21:2895-2900.

16. Thangapazham RL, Puri A, Tele S, Blumenthal R, Maheshwari RK. Evaluation of a nanotechnology-based carrier for delivery of curcumin in prostate cancer cells. Int J Oncol. 2008;32:1119-1123.

17. Li L, Braiteh FS, Kurzrock R. Liposome-encapsulated curcumin: in vitro and in vivo effects on proliferation, apoptosis, signaling, and angiogenesis. Cancer. 2005;104:1322-1331.

18. Han HD, Lee A, Hwang T, et al. Enhanced circulation time and antitumor activity of doxorubicin by comb like polymer-incorporated liposomes. J Control Release. 2007;120:161-168.

19. Laverman P, Brouwers AH, Dams ET, et al. Preclinical and clinical evidence for disappearance of long-circulating characteristics of polyethylene glycol liposomes at low lipid dose. J Pharmacol Exp Ther. 2000;293:996-1001.

20. Laverman P, Carstens MG, Boerman OC, et al. Factors affecting the accelerated blood clearance of polyethylene glycol-liposomes upon repeated injection. J Pharmacol Exp Ther. 2001;298:607-612.

21. Ishida T, Wang X, Shimizu T, Nawata K, Kiwada H. PEGylated liposomes elicit an anti-PEG IgM response in a T cell-independent manner. J Control Release. 2007;122(3):349-355.

22. Oerlemans C, Bult W, Bos M, Storm G, Nijsen JF, Hennink WE. Polymeric micelles in anticancer therapy: targeting, imaging and triggered release. Pharm Res. 2010;27:2569-2589.

23. Torchilin VP, Lukyanov AN, Gao Z, Papahadjopoulos-Sternberg B. Immunomicelles: targeted pharmaceutical carriers for poorly soluble drugs. Proc Natl Acad Sci U S A. 2003;100:6039-6044.

24. Musacchio T, Laquintana V, Latrofa A, Trapani G, Torchilin VP. PEG-PE micelles loaded with paclitaxel and surface-modified by a PBR-ligand: synergistic anticancer effect. Mol Pharm. 2009;6:468-479.

25. Vauthier C, Labarre D, Ponchel G. Design aspects of poly (alkylcyanoacrylate) nanoparticles for drug delivery. J Drug Target. 2007; 15:641-663.

26. Ambruosi A, Khalansky AS, Yamamoto H, Gelperina SE, Begley DJ, Kreuter J. Biodistribution of polysorbate 80-coated doxorubicinloaded $\left[{ }^{14} \mathrm{C}\right]$-poly(butyl cyanoacrylate) nanoparticles after intravenous administration to glioblastoma-bearing rats. J Drug Target. 2006;14: 97-105.

27. Ambruosi A, Gelperina S, Khalansky A, Tanski S, Theisen A, Kreuter J Influence of surfactants, polymer and doxorubicin loading on the antitumour effect of poly(butyl cyanoacrylate) nanoparticles in a rat glioma model. J Microencapsul. 2006;23:582-592.

28. Brigger I, Morizet J, Aubert G, et al. Poly(ethylene glycol)-coated hexadecylcyanoacrylate nanospheres display a combined effect for brain tumor targeting. J Pharmacol Exp Ther. 2002;303:928-936.

29. Brigger I, Morizet J, Laudani L, et al. Negative preclinical results with stealth nanospheres-encapsulated Doxorubicin in an orthotopic murine brain tumor model. J Control Release. 2004;100:29-40.

30. Duan J, Zhang Y, Han S, et al. Synthesis and in vitro/in vivo anti-cancer evaluation of curcumin-loaded chitosan/poly(butyl cyanoacrylate) nanoparticles. Int J Pharm. 2010;400:211-220.

31. Mulik RS, Monkkonen J, Juvonen RO, Mahadik KR, Paradkar AR. ApoE3 mediated poly(butyl) cyanoacrylate nanoparticles containing curcumin: study of enhanced activity of curcumin against beta amyloid induced cytotoxicity using in vitro cell culture model. Mol Pharm. 2010;7:815-825.

32. Brigger I, Chaminade P, Marsaud V, et al. Tamoxifen encapsulation within polyethylene glycol-coated nanospheres. A new antiestrogen formulation. Int J Pharm. 2001;214:37-42.

33. Stella B, Arpicco S, Rocco F, et al. Encapsulation of gemcitabine lipophilic derivatives into polycyanoacrylate nanospheres and nanocapsules. Int J Pharm. 2007;344(1-2):71-77.
34. Toub N, Bertrand JR, Tamaddon A, et al. Efficacy of siRNA nanocapsules targeted against the EWS-Fli1 oncogene in Ewing sarcoma. Pharm Res. 2006;23(5):892-900.

35. Yousefi A, Esmaeili F, Rshimian S, Atyabi F, Dinarvand R. Preparation and in vitro evaluation of a pegylated nano-liposomal formulation containing docetaxel. Sci Pharm. 2009;77:453-464.

36. Sharma R, Yasir M, Bhaskar S, Asif M. Formulation and evaluation of paclitaxel loaded PSA-PEG nanoparticle. J App Pharm Sci. 2011;1: 96-98

37. Nobs L, Buchegger F, Gurny R, Allmann E. Biodegradable nanoparticles for direct or two-step tumor immunotargeting. Bioconjug Chem. 2006;17:139-145.

38. Park JW, Hong K, Kirpotin DB, et al. Anti-HER2 immunoliposomes: enhanced efficacy attributable to targeted delivery. Clin Cancer Res. 2002;8:1172-1181.

39. Sun B, Ranganathan B, Feng SS. Multifunctional poly(D,L-lactide-coglycolide)/montmorillonite (PLGA/MMT) nanoparticles decorated by Trastuzumab for targeted chemotherapy of breast cancer. Biomaterials. 2008:29475-29486.

40. Day ES, Bickford LR, Slater JH, Riggall NS, Drezek RA, West JL. Antibody-conjugated gold-gold sulfide nanoparticles as multifunctional agents for imaging and therapy of breast cancer. Int $J$ Nanomedicine. 2010;5:445-454

41. Shahzad MM, Mangala LS, Han HD, et al. Targeted delivery of small interfering RNA using reconstituted high-density lipoprotein nanoparticles. Neoplasia. 2011;13:309-319.

42. Wu P, He X, Wang K, et al. Imaging breast cancer cells and tissues using peptide-labeled fluorescent silica nanoparticles. J Nanosci Nanotechnol. 2008;8:2483-2487.

43. Han HD, Mangala LS, Lee JW, et al. Targeted gene silencing using RGD-labeled chitosan nanoparticles. Clin Cancer Res. 2010;16: 3910-3922.

44. Farokhzad OC, Cheng J, Teply BA, et al. Targeted nanoparticle-aptamer bioconjugates for cancer chemotherapy in vivo. Proc Natl Acad Sci US A. 2006;103:6315-6320.

45. Salazar MD, Ratnam M. The folate receptor: what does it promise in tissue-targeted therapeutics? Cancer Metastasis Rev. 2007;26:141-152.

46. Kamen BA, Smith AK. A review of folate receptor alpha cycling and 5-methyltetrahydrofolate accumulation with an emphasis on cell models in vitro. Adv Drug Deliv Rev. 2004;56:1085-1097.

47. Antony AC. The biological chemistry of folate receptors. Blood. 1992;79:2807-2820.

48. Mathias CJ, Hubers D, Low PS, Green MA. Synthesis of [(99 m) Tc]DTPA-folate and its evaluation as a folate-receptor-targeted radiopharmaceutical. Bioconjug Chem. 2000;11:253-257.

49. Ulbrich K, Michaelis M, Rothweiler F, et al. Interaction of folateconjugated human serum albumin (HSA) nanoparticles with tumour cells. Int J Pharm. 2011;406:128-134.

50. Rossin R, Pan D, Qi K, et al. 64Cu-labeled folate-conjugated shell cross-linked nanoparticles for tumor imaging and radiotherapy: synthesis, radiolabeling, and biologic evaluation. J Nucl Med. 2005;46: 1210-1218.

51. Yang SJ, Lin FH, Tsai HM, et al. Alginate-folic acid-modified chitosan nanoparticles for photodynamic detection of intestinal neoplasms. Biomaterials. 2011;32:2174-2182.

52. Lee RJ, Low PS. Folate-mediated tumor cell targeting of liposomeentrapped doxorubicin in vitro. Biochim Biophys Acta. 1995;1233: 134-144.

53. Pan XQ, Wang H, Lee RJ. Antitumor activity of folate receptor-targeted liposomal doxorubicin in a $\mathrm{KB}$ oral carcinoma murine xenograft model. Pharm Res. 2003;20:417-422.

54. Choi H, Choi SR, Zhou R, Kung HF, Chen IW. Iron oxide nanoparticles as magnetic resonance contrast agent for tumor imaging via folate receptor-targeted delivery. Acad Radiol. 2004;11:996-1004.

55. Backer MV, Gaynutdinov TI, Patel V, et al. Vascular endothelial growth factor selectively targets boronated dendrimers to tumor vasculature. Mol Cancer Ther. 2005:1423-1429. 
56. Li L, Wartchow CA, Danthi SN, et al. A novel antiangiogenesis therapy using an integrin antagonist or anti-Flk-1 antibody coated 90Y-labeled nanoparticles. Int J Radiat Oncol Biol Phys. 2004;58:1215-1227.

57. Hood JD, Bednarski M, Frausto R, et al. Tumor regression by targeted gene delivery to the neovasculature. Science. 2002;296:2404-2407.

58. Gosk S, Moos T, Gottstein C, Bendas G. VCAM-1 directed immunoliposomes selectively target tumor vasculature in vivo. Biochim Biophys Acta. 2008:854-863.

59. Kirpotin DB, Drummond DC, Shao Y, et al. Antibody targeting of long-circulating lipidic nanoparticles does not increase tumor localization but does increase internalization in animal models. Cancer Res. 2006;66:6732-6740.

60. Pun SH, Tack F, Bellocq NC, et al. Targeted delivery of RNA-cleaving DNA enzyme (DNAzyme) to tumor tissue by transferrin-modified, cyclodextrin-based particles. Cancer Biol Ther. 2004;3:641-650.

61. Shmeeda H, Mak L, Tzemach D, Astrahan P, Tarshish M, Gabizon A. Intracellular uptake and intracavitary targeting of folate-conjugated liposomes in a mouse lymphoma model with up-regulated folate receptors. Mol Cancer Ther. 2006;5:818-824.

62. Jain RK. Normalization of tumor vasculature: an emerging concept in antiangiogenic therapy. Science. 2005;307:58-62.

63. Izumi Y, Xu L, Tomaso E, Fukumura D, Jain RK. Tumor biology: Herceptin acts as an anti-angiogenic cocktail. Nature. 2002;416:279-280.

64. Gazeau F, Lévy M, Wilhelm C. Optimizing magnetic nanoparticle design for nanothermotherapy. Nanomed. 2008;3:831-844.

65. Krishnan S, Diagaradjane P, Cho S. Nanoparticle-mediated thermal therapy: Evolving strategies for prostate cancer therapy. Int J Hyperthermia. 2011;26:775-789.
66. DeNardo GL, DeNardo SJ. Update: turning the heat on cancer. Cancer Biother Radiopharm. 2008;23:671-680.

67. Santosham R, Dev B, Priyadarshini P, et al. How I do it: Radiofrequency ablation. Indian J Radiol Imaging. 2008;18:166-170.

68. Merkle EM, Goldberg SN, Boll DT, et al. Effects of superparamagnetic iron oxide on radiofrequency-induced temperature distribution: in vitro measurements in polyacrylamide phantoms and in vivo results in a rabbit liver model. Radiology. 1999;212:459-466.

69. McBain SC, Yiu HH, Dobson J. Magnetic nanoparticles for gene and drug delivery. Int J Nanomedicine. 2008;3:169-180.

70. Thiesen B, Jordan A. Clinical applications of magnetic nanoparticles for hyperthermia. Int J Hyperthermia. 2008;24:467-474.

71. Roca AG, Costo R, Rebolledo AF, et al. Progress in the preparation of magnetic nanoparticles for applications in biomedicine. J Phys D: Appl Phys. 2009;42:224002-224012.

72. Ivkov R, DeNardo SJ, Daum W, et al. Application of high amplitude alternating magnetic fields for heat induction of nanoparticles localized in cancer. Clin Cancer Res. 2005;11:7093-7103.

73. Maier-Hauff K, Ulrich F, Nestler D, et al. Efficacy and safety of intratumoral thermotherapy using magnetic iron-oxide nanoparticles combined with external beam radiotherapy on patients with recurrent glioblastoma multiforme. J Neurooncol. 2011;103:317-324.

74. Occhipinti E, Verderio P, Natalello A, et al. Investigating the structural biofunctionality of antibodies conjugated to magnetic nanoparticles. Nanoscale. 2011;3:387-390.

75. Natarajan A, Xiong CY, Gruettner C, DeNardo GL, DeNardo SJ. Development of multivalent radioimmunonanoparticles for cancer imaging and therapy. Cancer Biother Radiopharm. 2008;23:82-91.
International Journal of Nanomedicine

\section{Publish your work in this journal}

The International Journal of Nanomedicine is an international, peerreviewed journal focusing on the application of nanotechnology in diagnostics, therapeutics, and drug delivery systems throughout the biomedical field. This journal is indexed on PubMed Central, MedLine, CAS, SciSearch $\AA$, Current Contents ${ }^{\circledR} /$ Clinical Medicine,

\section{Dovepress}

Journal Citation Reports/Science Edition, EMBase, Scopus and the Elsevier Bibliographic databases. The manuscript management system is completely online and includes a very quick and fair peer-review system, which is all easy to use. Visit http://www.dovepress.com/ testimonials.php to read real quotes from published authors. 